\title{
The use of isoxazoline and isoxazole scaffolding in the design of novel thiourea and amide liquid-crystalline compounds
}

\author{
Itamar L. Gonçalves ${ }^{1}$, Rafaela R. da Rosa ${ }^{2}$, Vera L. Eifler-Lima ${ }^{1}$ and Aloir A. Merlo*3
}

\author{
Full Research Paper \\ Address: \\ ${ }^{1}$ Laboratório de Síntese Orgânica Medicinal/LaSOM, Faculdade de \\ Farmácia, Universidade Federal do Rio Grande do Sul, Avenida \\ Ipiranga, Porto Alegre/RS, Brazil, ${ }^{2}$ CENIMAT/i3N, Departamento de \\ Ciência dos Materiais, Faculdade de Ciências e Tecnologia, \\ Universidade NOVA de Lisboa, 2829-516 Caparica, Portugal and \\ ${ }^{3}$ Institute of Chemistry, Universidade Federal do Rio Grande do Sul, \\ Porto Alegre, RS, Brazil \\ Email: \\ Aloir A. Merlo* - aloir.merlo@ufrgs.br \\ * Corresponding author \\ Keywords: \\ amides; isoxazole; isoxazoline; liquid crystal; thiourea \\ Beilstein J. Org. Chem. 2020, 16, 175-184. \\ doi:10.3762/bjoc. 16.20 \\ Received: 27 June 2019 \\ Accepted: 24 January 2020 \\ Published: 06 February 2020 \\ Associate Editor: T. J. J. Müller \\ (C) 2020 Gonçalves et al.; licensee Beilstein-Institut. \\ License and terms: see end of document.
}

\begin{abstract}
A series of novel thiourea and amide liquid crystals containing 5-membered isoxazoline and isoxazole rings were synthetized and the liquid crystal properties studied. Thioureas were obtained using a condensation reaction of benzoyl chlorides, arylamines and ammonium thiocyanate. The amides, on the other hand, were the byproduct of a quantitative reaction which used potassium cyanate as the starting material. Thiourea and amide derivatives were predominantly SmA mesophase inductors. A nematic mesophase was observed only for thioureas and amides containing an isoxazole ring. Additionaly, the liquid crystal behavior was also dependent on the relative position of nitrogen and oxygen atoms on the 5-membered heterocycle.
\end{abstract}

\section{Introduction}

Thioureas are a structurally diversified group of organic compounds, with technological applications in different areas. The structural diversity of the thiourea moiety is linked to possibly one or both nitrogen components, which may be substituted symmetrically or unsymmetrically [1]. Applications of this scaffold include complexing agents in anion sensors [2] organocatalysts [3], intermediates in heterocycle synthesis [1] and development of compounds with pharmacological effects [4].
Considering the importance of this group of molecules, numerous strategies have been developed for their preparation. Substituted thioureas can be obtained using a variety of approaches although the simplest route involves the heating of ammonium thiocyanate with an amine in an aqueous acid medium [5]. They can also be synthesized in the reaction of thiourea with primary amines [6]. Another important synthetic route for substituted thioureas is a two-step approach: (i) the addition/elimination 
reaction of benzoyl chloride, with a thiocyanate salt, generating in situ, benzoyl isothiocyanate, and (ii) an appropriate amine reaction with benzoyl isothiocyanate, yielding the acylthiourea which may be the final product or may be hydrolyzed to obtain the monosubstituted thiourea $[7,8]$. An alternative and versatile route for generating isothiocyanate for the use in the preparation of disubstituted symmetrical and unsymmetrical thioureas is the reaction of carbon disulfide with either one or two different amines [9].

Due to their self-assembly and self-organization through intermolecular hydrogen bonding, thioureas display interesting technological applications to this group of molecules, one of which explores its application in liquid crystal design [10,11]. $N, N^{\prime}-$ Bis(3,4,5-trialkoxylphenyl)ureas were identified as columnar liquid crystalline compounds presenting ferroelectric properties [12]. Another study reported cyclic disubstituted ureas with liquid crystalline ferroelectric and antiferroelectric phases [13] Relating to the thiourea moiety, there is only one recent report, in which some derivatives of $N$-benzoyl- $N$ '-arylthiourea with liquid crystalline properties have been investigated [14].

One aspect that compounds forming hydrogen bonds, such as ureas, thioureas, amides etc. for the use in electronic devices is the ability to establish intra- and intermolecular hydrogen bonds [11]. In addition to $\pi-\pi$, dipole-dipole and van der Waals interactions, hydrogen bond interactions are involved in gel formation through self-aggregation of the small gelator molecules. In recent years, there has been increased interest in the study of gels derived from low molecular mass gelators $[15,16]$, and consequently the investigation of gelators of low molar mass with liquid crystal proprieties remains active $[17,18]$.

In addition, isoxazolines and isoxazoles have been identified as promising templates in liquid crystal development, mainly due to their structural and electronic features. Isoxazoline and isoxazole cores show strong dipole moments, polarizabilities, anisotropic interactions and geometrical aspects that favor the formation of stable smectic A and nematic mesophases, respectively $[19,20]$. This work aimed at synthetizing new thioureas and amides by the installation of mesogenic cores derived from isoxazoline and isoxazole scaffolds and 4- $n$-alkoxybenzoic acid with liquid crystal properties. The liquid crystal properties of the compounds were investigated by polarized optical microscopy analysis (POM) and differential scanning calorimetry (DSC).

\section{Results and Discussion Synthesis}

In order to generate molecular structural diversity in thioureas, three sets of amines carrying 5-membered isoxazolines/isoxa- zoles (see Scheme 1) were employed and condensed with acyl isothiocyanates, as outlined in Scheme 2. Amines 3, 4, 8, 9, 12 and $\mathbf{1 3}$ were then prepared by [3 + 2]-1,3-dipolar cycloaddition of nitrile oxide (ArCNO) formed in situ from oximes and a number of alkenes as dipolarophiles, to yield the precursors of the cycloadducts isoxazolines $\mathbf{2 , 7}$ and $\mathbf{1 1}$ regioselectively. The cycloadducts were subjected to $\mathrm{SnCl}_{2}$ reduction to yield amines 4, 9 and 13 containing an isoxazoline ring. The amines 3,8 and 12 containing an isoxazole ring were synthesized in two sequential steps - first a $\mathrm{MnO}_{2}$ oxidation step transforming the isoxazoline ring to an isoxazole ring followed by $\mathrm{SnCl}_{2}$ reduction, according to protocols previously published $[19,21$ 24].

The synthetic route used for the synthesis of the hybrid compounds, $N$-acyl- $N$ '-isoxazolinylthioureas $17 \mathbf{a}-\mathbf{c}$ and $N$-acyl- $N$ 'isoxazolylthioureas 18a-c is outlined in Scheme 2. The synthesis of thioureas $17 \mathbf{a}-\mathbf{c}$ and $18 \mathbf{a}-\mathbf{c}$ involved the activation of 4-heptyloxybenzoic acid (14) to its chloride 15, which was submitted to an acyl nucleophile substitution reaction using ammonium thiocyanate as the nucleophile. This yielded the corresponding acyl isothiocyanate $\mathbf{1 6}$. The solid residue formed was used directly without further isolation and purification. The additional reaction between the acyl isothiocyanate $\mathbf{1 6}$ and amines $\mathbf{3}, 4,8,9,12$ and 13 yielded the title compounds $17 \mathbf{a}-\mathbf{c}$ and 18a-c in $56-62 \%$ yields $(17$ a $57 \% ; 17$ b $56 \% ; 17$ c $58 \%$; 18 a $61 \% ; \mathbf{1 8 b} 60 \% ; \mathbf{1 8 c} 62 \%)$.

In an attempt to improve the structural diversity of thioureas, potassium cyanate was used as a nucleophile instead of the thiocyanate salt, following the same experimental protocol. However, when a cyanate salt was used, only the amides 19-22 were isolated as the main products. The target ureas were not obtained, according to Scheme 3, part A. To test the hypothesis of intermediate formation of acyl cation $[\mathrm{ArCO}]^{+}$during the condensation reaction of thiocyanate salt, a reaction test was performed to confirm the reactivity between the amines and acyl chloride. This involved the formation and isolation of amide $\mathbf{2 4}$, as a result of the reaction between the reactive intermediate nonyloxybenzoyl chloride from acid 23 and the amine 4 (Scheme 3, part B). Attempts to improve the reactivity of potassium cyanate by adding crown ethers did not result in the formation of ureas as expected. Thus, five new amides 19-22 and 24 were obtained in yield range of 42-71\% (19 42\%; 20 53\%; 21 58\%; 22 53\%; 24 71\%).

\section{Mesomorphic properties}

Mesomorphic properties of thioureas 17a-c, and 18a-c and amides 19-22 and 24 were investigated by POM and DSC. The DSC results for all compounds are summarized in Table 1. 
<smiles>O=Cc1ccc([N+](=O)[O-])cc1</smiles>

1

route $A$
1. oximation reaction

2. [3 + 2]-1,3-dipolar

cycloaddition

3. deprotection

4. alkylation reaction

refs $[19,21,23]$<smiles>[3H]CCOc1ccc(-c2cc(-c3ccc(N)cc3)no2)cc1</smiles>

3<smiles>O=[N+]([O-])c1ccc(C2=NOC(c3ccc(OC4CCCCC4)cc3)C2)cc1</smiles>

2

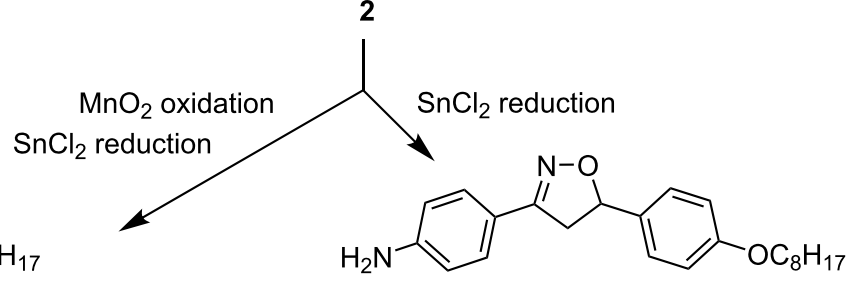

4<smiles>O=Cc1ccc(O)cc1</smiles>

5

route $B$

1. alkylation reaction

2. oximation

3. [3+2]-1,3-dipolar cycloaddition

6 from 1 by

Wittig reaction<smiles>C=Cc1ccc([N+](=O)[O-])cc1</smiles>

refs $[21,22]$

$\mathrm{SnCl}_{2}$ reduction<smiles>O=[N+]([O-])c1ccc(C2CC(c3ccc(O[GaH])cc3)=NO2)cc1</smiles>

7<smiles>CCOc1ccc(-c2cc(-c3ccc(N)cc3)on2)cc1</smiles><smiles>CCOc1ccc(C2=NOC(c3ccc(N)cc3)C2)cc1</smiles>

8<smiles>CCCCCCCO</smiles>

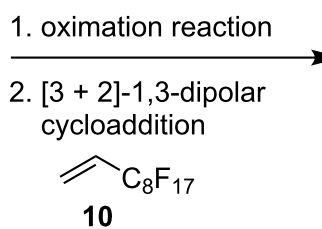
ref [21]<smiles>Nc1ccc(-c2cc(C(F)F)on2)cc1</smiles><smiles></smiles>

13

Scheme 1: Amines 3, 4, 8, 9, 12 and 13 installed on 5-membered isoxazoline and isoxazole rings.

Transition temperatures, as well as the enthalpy and entropy values of each compound were acquired by differential scanning calorimetry (DSC). The transition temperature peak was considered for all compounds and tabulated, using the first heating curve, as well the values for $\Delta H$ and $\Delta S$ associated with each transition (see Table 1). Six liquid crystallines (LCs) thioureas were synthesized and studied and divided into two groups containing isoxazoline rings $\mathbf{1 7 a}-\mathbf{c}$ and isoxazoles 18a-c, as well as LCs amides 19-22 and 24. All compounds listed in Table 1 are capable of self-organization by hydrogen bonds, either in their solid state or in solution. Solubility in protic or aprotic polar solvent is restricted at room temperature. 


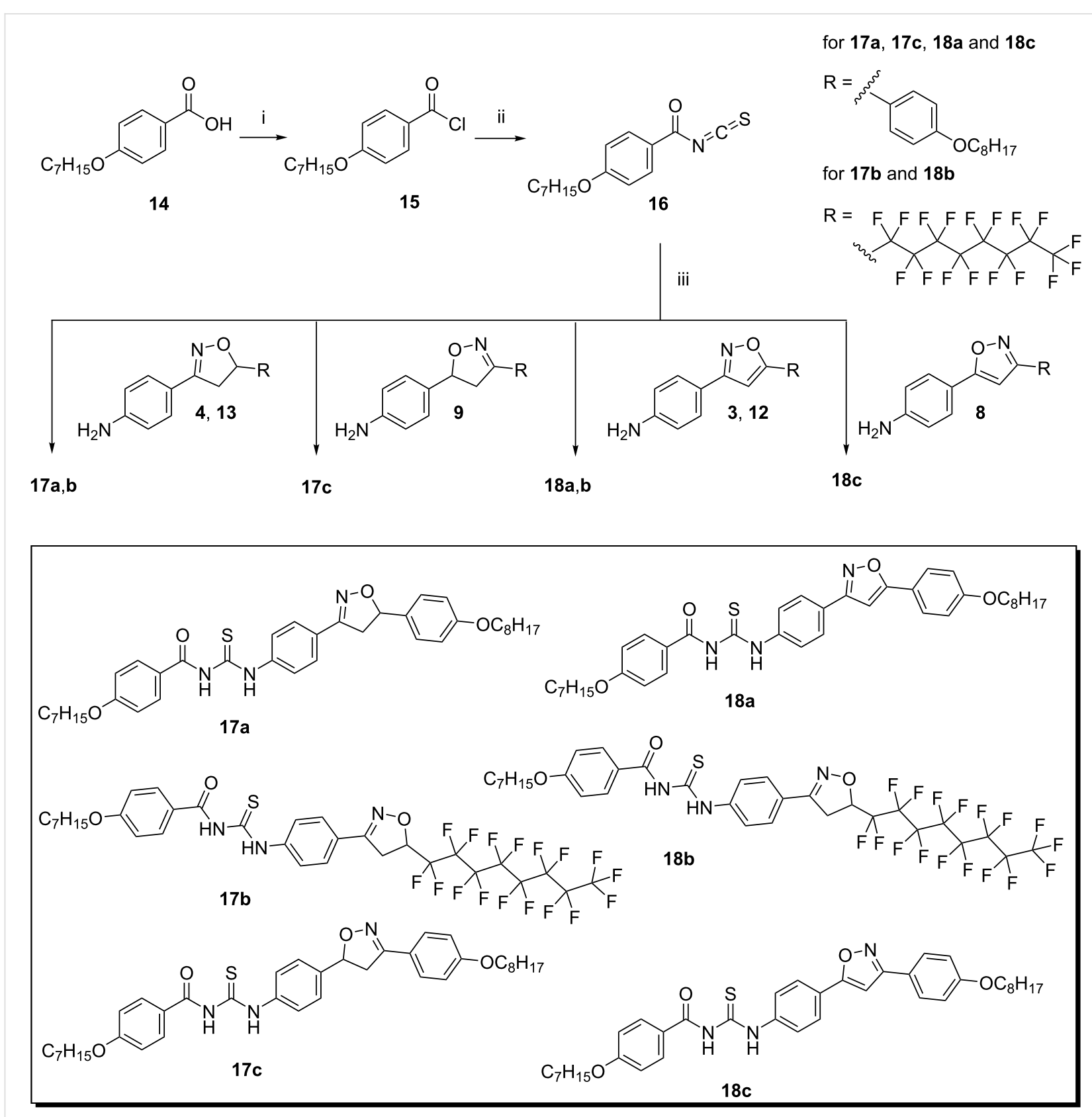

Scheme 2: Synthesis of acylisoxazolinylthioureas $\mathbf{1 7 a}-\mathbf{c}$ and acylisoxazolylthioureas $\mathbf{1 8 a}-\mathbf{c}$. (i) $\mathrm{SOCl}_{2}$, reflux, 2 h; (ii) $\mathrm{NH}_{4} \mathrm{SCN}$, acetone, reflux 40 minutes; (iii) acetone, reflux.

However, they become almost soluble in a hot solution of polar solvents, and when cooled, precipitate into an amorphous solid, limiting their use as gelators.

A mesomorphic behavior was observed for thioureas $\mathbf{1 7} \mathbf{a}-\mathbf{b}$, 18a-c and amides 19, 20, 22 and 24. Thiourea 17c and amide 21 did not display mesomorphic behavior. A smectic A mesophase (SmA) was preponderant in this study. However, a nematic mesophase $(\mathrm{N})$ appeared for thioureas $18 \mathbf{a}$ and $18 \mathrm{c}$ and amide 20. Thioureas $\mathbf{1 7 b}, \mathbf{1 8 b}$ and $\mathbf{1 8 c}$ and amides 19, 20, 22 and 24 displayed an enantiotropic SmA mesophase, except thiourea 17a which showed a monotropic SmA mesophase. A monotropic smectic C mesophase $(\mathrm{SmC})$ at $198{ }^{\circ} \mathrm{C}$ was observed for amide 19. Perfluorinated thioureas $17 \mathrm{~b}$ and $\mathbf{1 8 b}$ presented an SmA mesophase, independent of the nature of the 5-membered heterocycle. The perfluorinated alkyl chain in both compounds is the reason of preference for a lamellar SmA behavior $[25,26]$ by segregation effects. Interestingly, isoxazoline 17a presented a monotropic SmA mesophase, while its regioisomer 17c did not show a mesophase. Corresponding isoxa- 


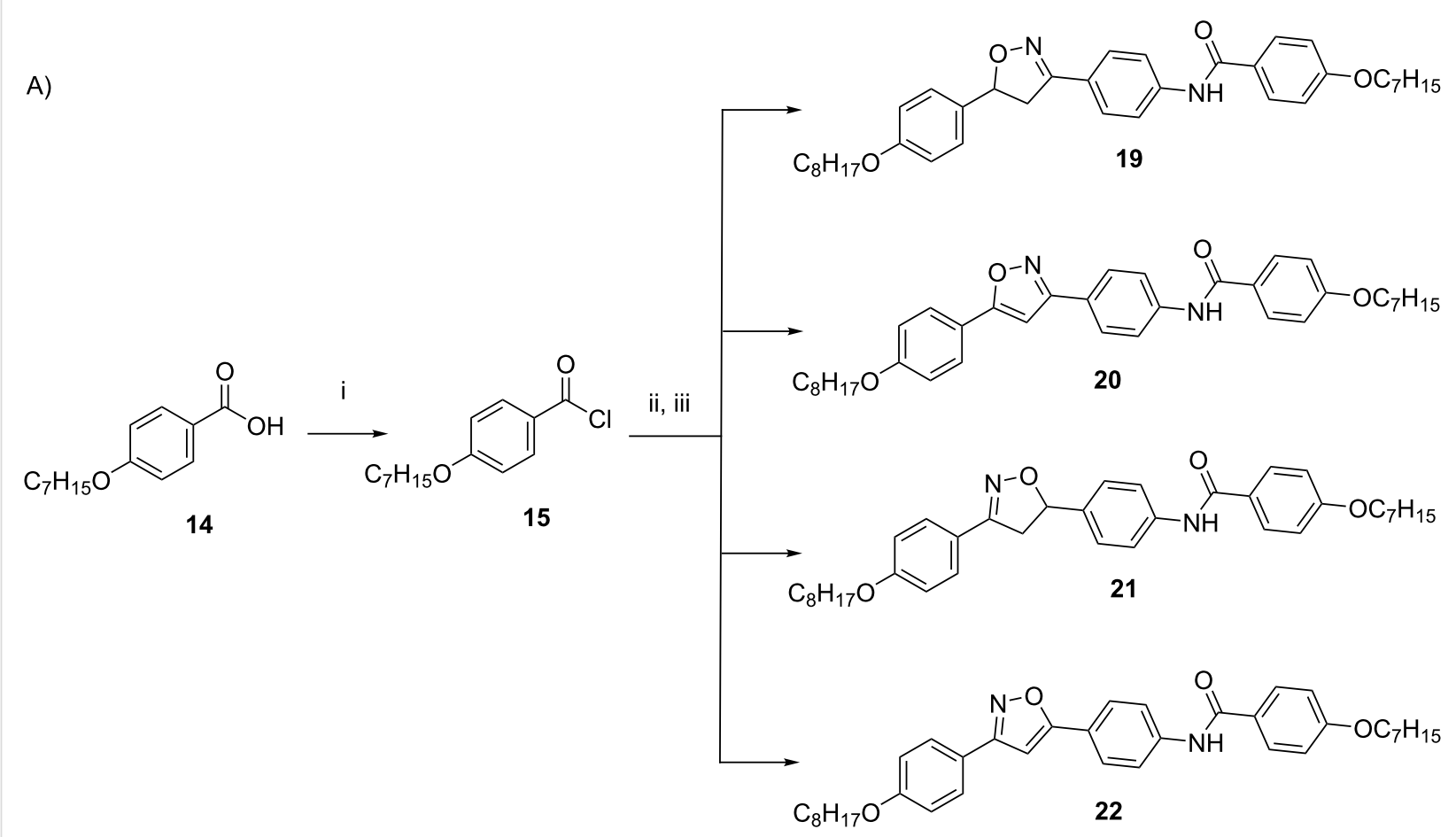

B)<smiles>CCOc1ccc(C(=O)O)cc1</smiles>
23

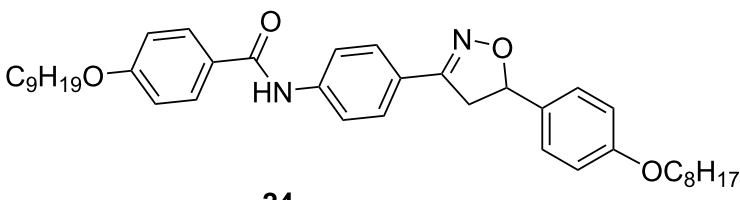

24

Scheme 3: Synthesis of amides. Part A: (i) $\mathrm{SOCl}_{2}$, reflux; (ii) $\mathrm{KOCN}$, acetone, reflux; (iii) amines 3, 4, 8 and 9, acetone, reflux. Part B: (i) $\mathrm{SOCl}_{2}$, reflux; (ii) amine $\mathbf{4}$, acetone, reflux.

zoles formed stable mesophases as expected ( $\mathrm{N}$ for $\mathbf{1 8 a} ; \mathrm{SmA}$ and $\mathrm{N}$ for 18c) [20].

Figure 1 shows the selected textures of the thiourea series observed under POM. Upon cooling, the fan-shaped focal conic texture of the SmA mesophase was formed for 17a (Figure 1a), 17b (Figure 1b), 18b (Figure 1d) and 18c (Figure 1e). A nematic mesophase $(\mathrm{N})$ was assigned for thioureas 18a (Figure 1c) and 18c by the schlieren texture described in Figure 1f.

Figure 2 displays the textures recorded for amide 19. Upon cooling, amide 19 enters the SmA mesophase as evidenced by the fan-shaped focal conic texture (Figure 2a) at $201{ }^{\circ} \mathrm{C}$. At $198^{\circ} \mathrm{C}$, the texture of the sample under analysis becomes blurred. This is indicative of a broken fan-shaped focal conic SmC texture (Figure 2b). Visual inspection in other domains at the same temperature revealed the existence of a schlieren texture (Figure 2c) which corresponds to the monotropic SmC mesophase assignment for amide $\mathbf{1 9}$.
The liquid crystal data tabulated in Table 1 allow to correlate structures and properties of the thioureas and amides. The first comments will be addressed to general aspects of thiourea DSC thermograms. Upon heating, for the first time, peaks can be clearly identified, associated with transition between phases and the thermal history of the samples. Unfortunately, upon cooling, intensity, resolution and peaks of some phase transitions are lost. Considering that molecules self-organize upon cooling, first by hydrogen bonds followed by $\pi$-stacking and van der Waals forces, DSC scanning at $10{ }^{\circ} \mathrm{C} / \mathrm{min}$ is too fast to allow the molecules to self-assemble in a perfect $3 \mathrm{D}$ matrix. Even with a scan rate of more than $10{ }^{\circ} \mathrm{C}$, it was not possible to reproduce the peaks reported during the first scan.

The thermal behavior of the thioureas in this study is similar to that of polymers becoming semicrystalline or an amorphous solid after subjecting them to repeated heating and cooling cycles. Figure $3 \mathrm{a}$ is illustrative of the thermal behavior mentioned above for thiourea 17a. Upon cooling, peaks tend to be less intense and flatter. The DSC thermograms for amides 
Table 1: Phase transition temperatures $\left({ }^{\circ} \mathrm{C}\right)$, enthalpy/entropy for thioureas $17 \mathrm{a}-\mathrm{c}, \mathbf{1 8 a}-\mathrm{c}$ and amides $19-22$ and 24 upon heating. ${ }^{\mathrm{a}}$

\begin{tabular}{|c|c|c|c|c|c|c|c|c|c|}
\hline LC & $\mathrm{Cr}$ & & $\mathrm{SmC}$ & & SmA & & $\mathrm{N}$ & & \\
\hline $17 a$ & $\bullet$ & $157^{\mathrm{b}}(6.57 / 15.27)$ & & - & $\bullet$ & $\{146\}$ & & - & $\bullet$ \\
\hline $17 b$ & $\bullet$ & $154(5.66 / 13.26)$ & & - & $\bullet$ & $234^{c}$ & & - & $\bullet$ \\
\hline $17 c$ & $\bullet$ & $116^{\mathrm{b}, \mathrm{d}}(2.21 / 5.57)$ & & - & & - & & - & $\bullet$ \\
\hline $18 a$ & $\bullet$ & $134(7.15 / 17.63)$ & & - & & - & $\bullet$ & $211(0.37 / 0.76)$ & $\bullet$ \\
\hline $18 b$ & $\bullet$ & $134(5.72 / 14.05)$ & & - & - & $217^{c}$ & & - & $\bullet$ \\
\hline $18 c$ & $\bullet$ & $141^{\mathrm{e}}(9.23 / 22.26)$ & & - & $\bullet$ & $201^{f}$ & $\bullet$ & $202^{\dagger}(0.07 / 0.14)$ & $\bullet$ \\
\hline 19 & $\bullet$ & $201(6.83 / 14.42)$ & $\bullet$ & $\{198\}$ & $\bullet$ & $207(5.14 / 10.68)$ & & - & $\bullet$ \\
\hline 20 & $\bullet$ & $202(5.98 / 12.58)$ & & - & $\bullet$ & $271(0.59 / 1.09)$ & $\bullet$ & $278(0.30 / 0.55)$ & $\bullet$ \\
\hline 21 & $\bullet$ & $197^{d}(13.53 / 28.85)$ & & - & & - & & - & $\bullet$ \\
\hline 22 & $\bullet$ & $208(6.85 / 14.24)$ & & - & $\bullet$ & $>250$ & & - & $\bullet$ \\
\hline 24 & $\bullet$ & $192^{\mathrm{b}}(4.35 / 9.35)$ & & - & $\bullet$ & $206(9.17 / 19.12)$ & & - & • \\
\hline
\end{tabular}

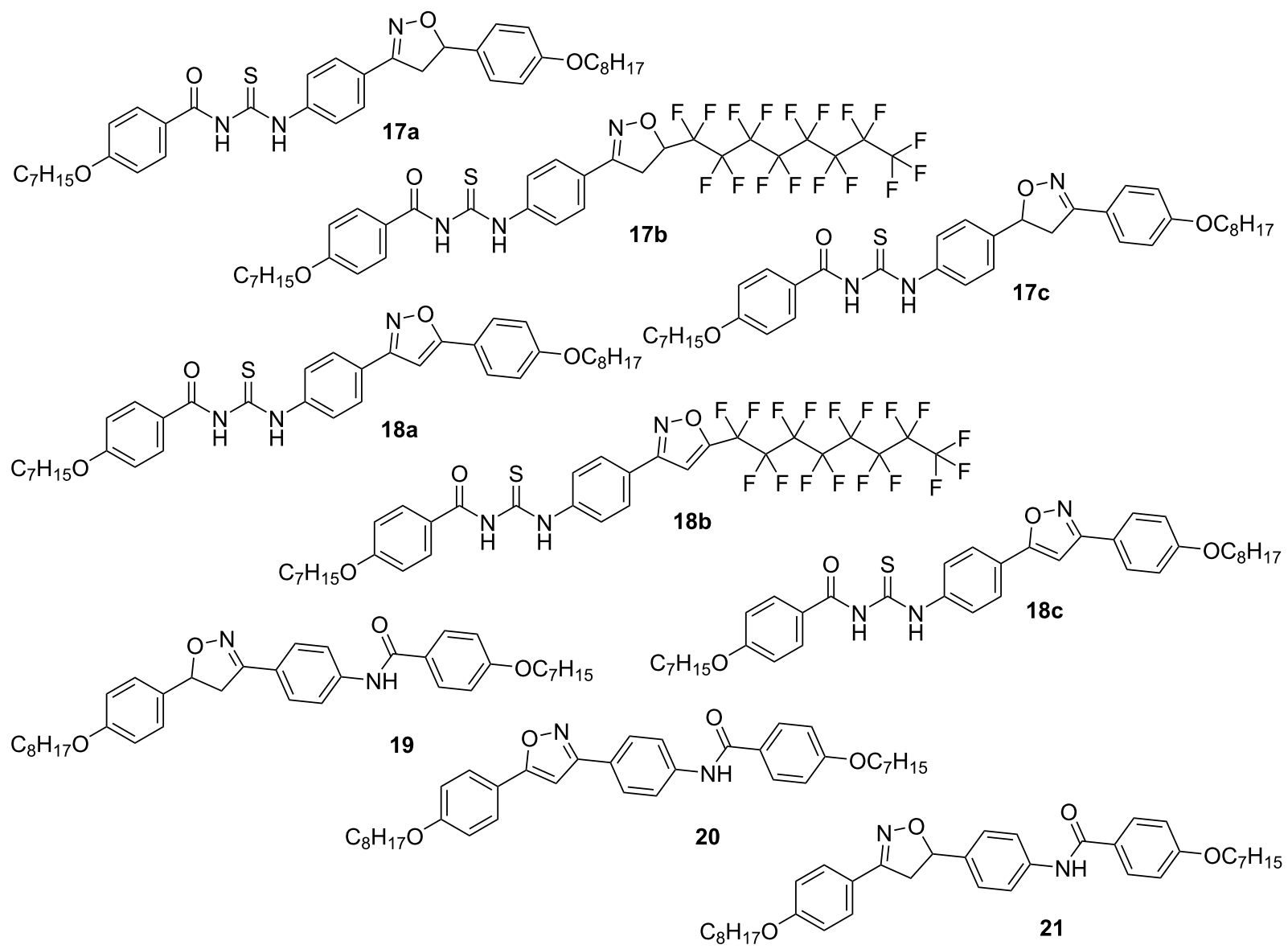<smiles>CCCCCOc1ccc(C(=O)Nc2ccc(-c3cc(-c4ccc(OCCC)cc4)no3)cc2)cc1</smiles><smiles>[Z4]CCCCOc1ccc(C(=O)Nc2ccc(C3=NOC(c4ccc(OCCC)cc4)C3)cc2)cc1</smiles>

${ }^{a}$ Data was recorded from the first curve upon heating. $\mathrm{Scan} 10^{\circ} \mathrm{C} / \mathrm{min} . \mathrm{Cr}=$ crystal phase; $\mathrm{SmC}=$ smectic $\mathrm{C}$ mesophase; $\mathrm{SmA}=$ smectic $\mathrm{A}$ mesophase; $\mathrm{N}=$ nematic mesophase and $\mathrm{I}=$ isotropic phase. Enthalpy and entropy values are given between parentheses in $\mathrm{kcal}_{\mathrm{mol}}^{-1}$ and $\mathrm{cal} \mathrm{mol}{ }^{-1} \mathrm{~K}^{-1}$, respectively. The curly brackets \{\} represent a monotropic transition temperature. ${ }^{\circ}$ Other peaks are seen in DSC thermograms below this temperature associated with the thermal history of the sample. ${ }^{c}$ Decomposition was observed when the sample reached this temperature. ${ }^{\mathrm{d}} \mathrm{No}$ mesophase was detected. e Unresolved shoulder peak at the left side which may be linked to another crystal-crystal transition. ${ }^{\mathrm{f}}$ Thermal decomposition started above $200{ }^{\circ} \mathrm{C}$ and nematic mesophase coexisted with the isotropic phase until $219^{\circ} \mathrm{C}$. 


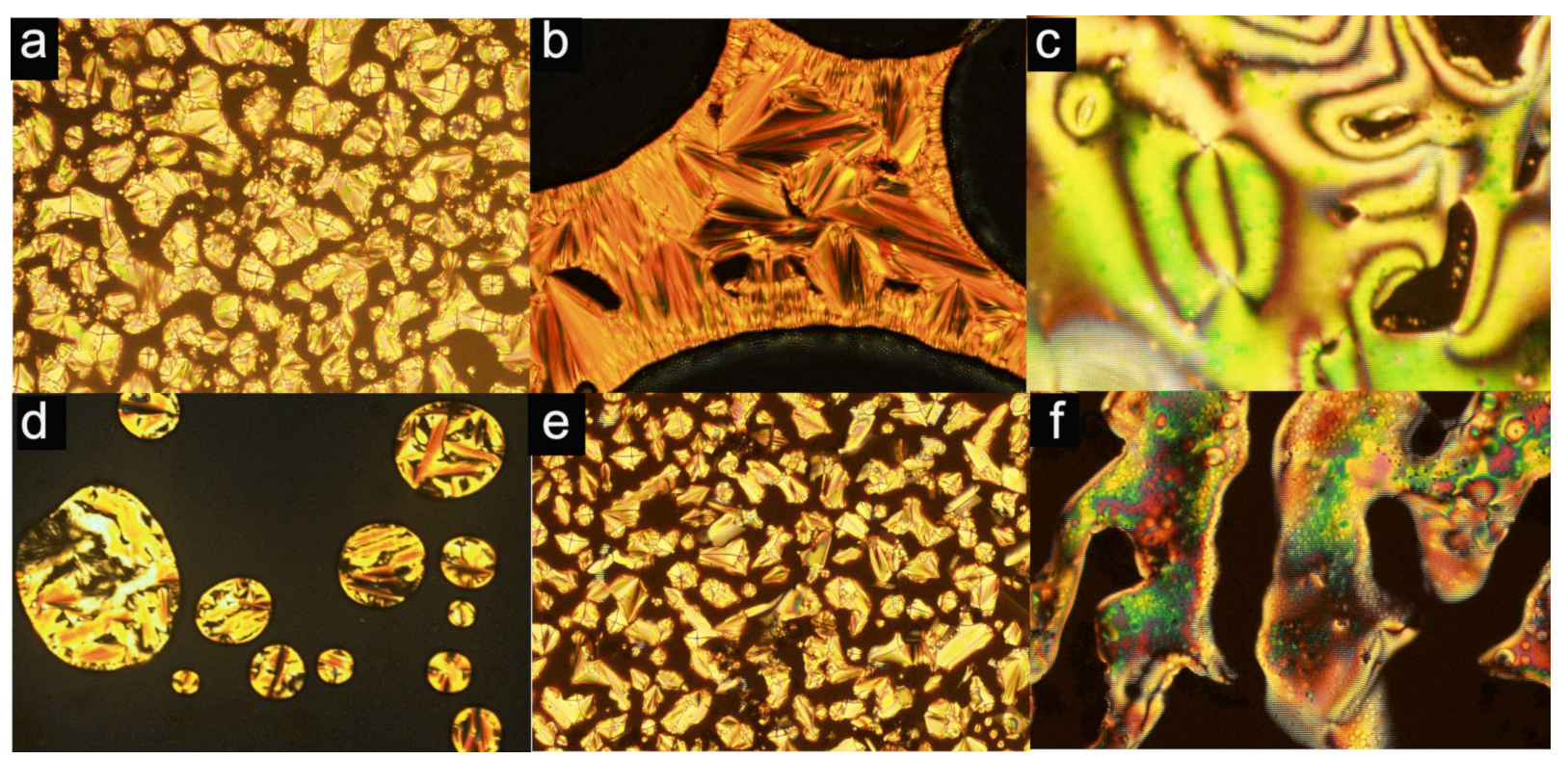

Figure 1: Optical textures observed on POM for thioureas $17 a(a), 17 b(b), 18 a(c), 18 b(d)$ and $18 c$ (e,f). All images were obtained upon cooling from the isotropic phase with the exception of (b). The "grid aspect" found in images (c) and (f) is an artifact due to the fast movement of the fluid mesophase.

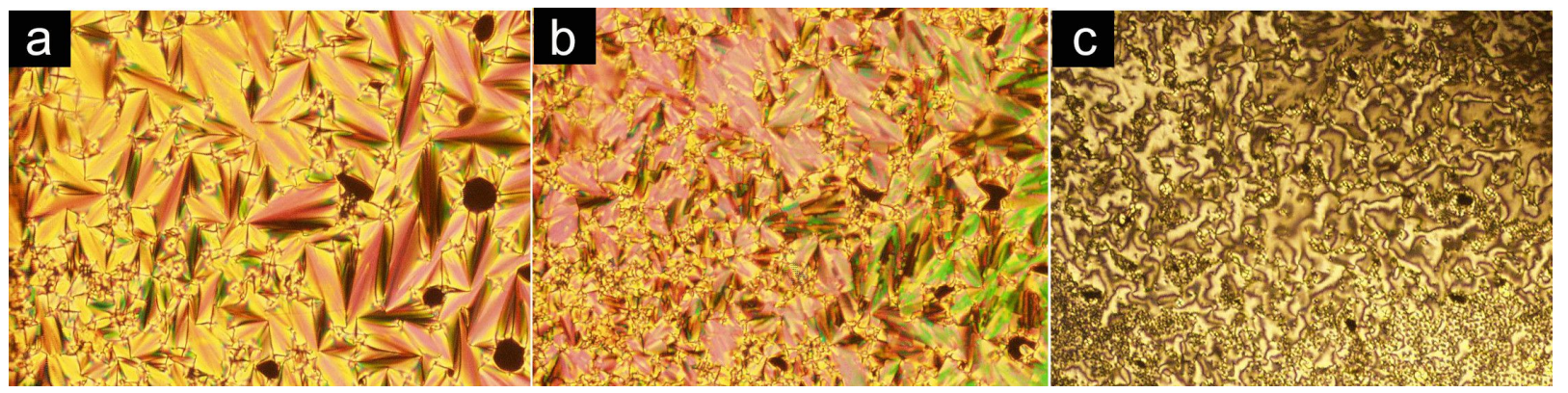

Figure 2: Optical textures observed on POM of amide 19. (a) Fan-shaped focal conic texture of the SmA mesophase upon cooling at $201^{\circ} \mathrm{C}$; (b) and (c) broken fan-shaped focal conic and schlieren textures of the SmC mesophase upon cooling at $198{ }^{\circ} \mathrm{C}$.

such as 19, during periods of heating and cooling, display peaks which correspond to the transition between crystal and mesomorphic phases. Figure $3 b$ and Figure $3 c$ describe DSC traces for first heating and cooling curves at $10{ }^{\circ} \mathrm{C} / \mathrm{min}$ of amides 19 and 20. Some peaks observed during the first heating cycle are not seen anymore in the second or third heating/cooling cycles due to the thermal history of the samples. Additional DSC graphs may be accessed in Supporting Information File 2.

Thioureas containing isoxazoline rings $\mathbf{1 7} \mathbf{a}-\mathbf{c}$ are not prone to show a mesophase, except when they have some special feature that intensifies the segregate character at molecular level [22]. Thus, while 17a showed a monotropic SmA mesophase, 17b with a perfluorinated alkyl chain, displayed enantiotropic SmA mesophase with a mesophase range of $\Delta T=80^{\circ} \mathrm{C}$. Perfluorinated and hydrogenated alkyl chains linked to isoxazoline and isoxazole scaffolds were previously studied in liquid crystal compounds [22]. The incidence of the SmA mesophase was intensified due to the segregation effect of perfluorinated and hydrogenated chains present in $\mathbf{1 7 b}$. For $\mathbf{1 7} \mathbf{c}$ the absence of LC properties could be related to the disrupt the planarity and electronic conjugation between the phenyl rings caused by the inversion of isoxazoline ring - its isomer $\mathbf{1 7} \mathbf{a}$, despite is monotropic behavior displayed SmA mesophase.

A similar liquid crystal behavior can be seen in amides 19 and 21 where the isomers differ only in the relative orientation of the isoxazoline ring to the amide group, while the amide group 

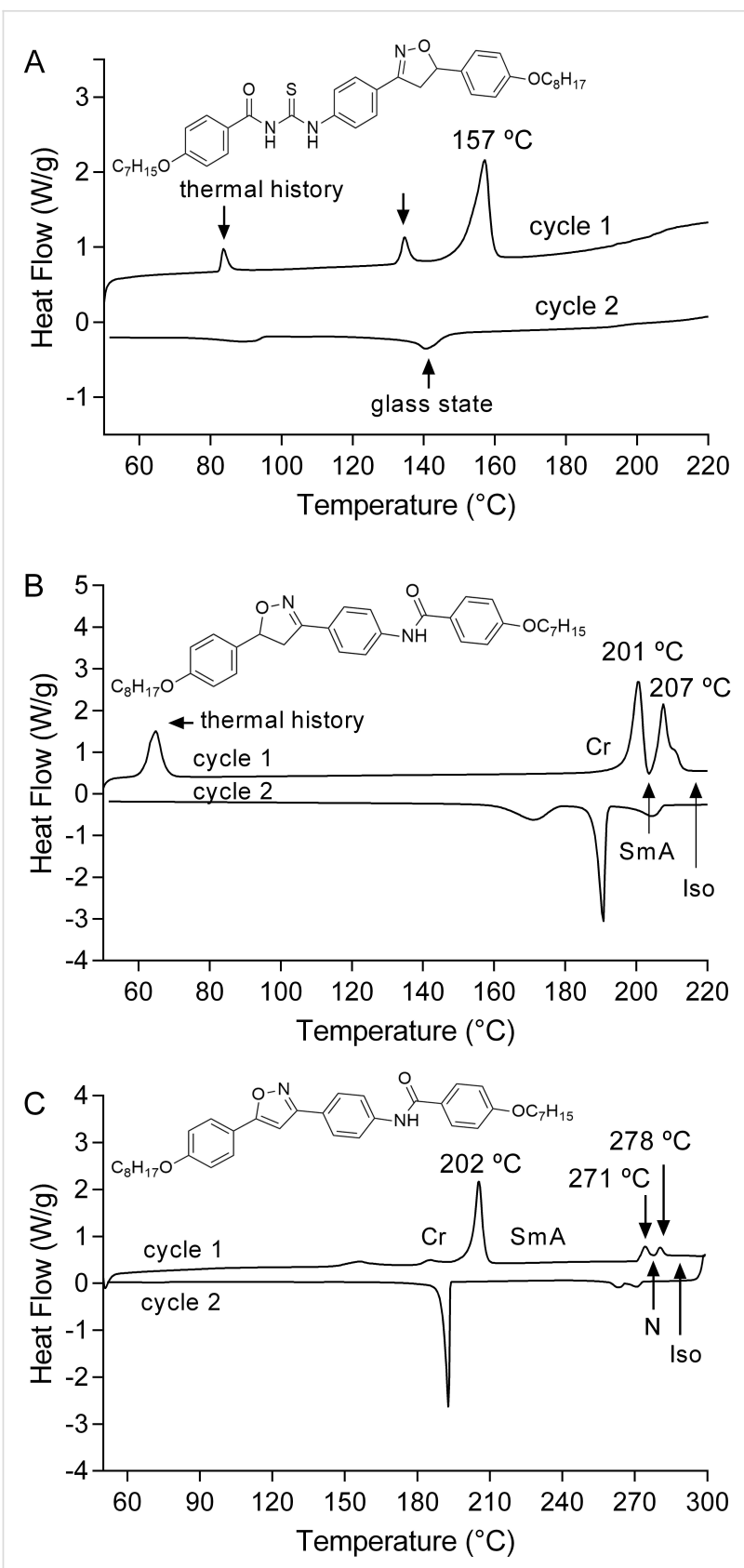

Figure 3: DSC curves for the thiourea 17a (A), amide $19(\mathrm{~B})$ and 20 (C) upon the first heating and cooling curve at a rate of $10^{\circ} \mathrm{C} \cdot \mathrm{min}^{-1}$.

in $\mathbf{1 9}$ can resonate to the nitrogen atom in the isoxazoline ring, 21 does not.

All analogous compounds such as thiourea 18a,b, containing an isoxazole ring, displayed enantiotropic SmA and $\mathrm{N}$ mesophases, confirming that the isoxazole ring favors the formation of a stable mesophase. It is interesting to notice that the nematic mesophase appeared only in compounds with the isoxazole ring (18a, 18c and 20), confirming that a longitudinal diffusion is favored for this type of LC compounds [19].
For the amides an SmA mesophase was found in 19, 20, 22 and 24. The liquid crystal mesophase ranges for these amides are dependent on the 5-membered ring connecting the aryl groups. Thus, 19 and 20 display an SmA mesophase range $(\Delta T)$ of $6{ }^{\circ} \mathrm{C}$ and $69^{\circ} \mathrm{C}$, respectively. Another example are amides $\mathbf{2 1}$ and $\mathbf{2 2}$. While $\mathbf{2 1}$ is not a LC, 22 displays a range of a mesophase of $>42{ }^{\circ} \mathrm{C}$. Examples above are representatives of the influence of 5 -membered heterocycle on the mesomorphic behavior. Thus, isoxazoline derivatives induce the formation of an SmA mesophase by lateral diffusion, while isoxazole derivatives favor the formation of a nematic mesophase by longitudinal diffusion, along SmA mesophase [27].

In addition, for amide 19, a second smectic mesophase was identified by POM as the monotropic SmC phase (Table 1, Figure 2). The transition to the SmC phase was not found in DSC analysis (Figure 3), due to its low transition enthalpy value. The transition from $\mathrm{SmA}$ to $\mathrm{SmC}$, passing through broken fan-shaped focal conic texture for compound $\mathbf{1 9}$ is shown in Figure 2. Amide 20 displayed polymorphism $\mathrm{Cr} \rightarrow$ $\mathrm{SmA} \rightarrow \mathrm{N} \rightarrow \mathrm{I}$.

The DSC graphs for amides 19, 20 and $\mathbf{2 4}$ showed a reproducible behavior in successive heating curves. This fact was not observed in the thiourea series 17a-c and 18a-c. In this series, a loss of signals corresponding to thermal transitions was observed in the third and fourth curves on the DSC graphs. This finding is detailed on the DSC graph for compounds 17a, 19 and 20 (see Figure 3). The thermal changes in DSC may be interpreted by intermolecular hydrogen bonds, which can be established between thiourea molecules in their solid state or in the liquid crystal mesophases. Liquid crystals containing hydrogen bonds may exhibit a wide variety of phase polymorphism depending on the length of the chain, type of bonding and the functional groups involved [12,28-30]. Many liquid crystalline compounds have been developed exploring the ability of hydrogen bonding formation between dissimilar moieties, such as alkyloxybenzoic acids [31] and alkylbenzoic and dodecane dicarboxylic acids [32].

The thioureas, with a perfluorinated chain, $\mathbf{1 7 b}$ and $\mathbf{1 8 b}$, presented thermal decomposition according to the DSC graphs, at temperatures above $200{ }^{\circ} \mathrm{C}$. These compounds were not analyzed by termal gravimetric analysis (TGA) due to the possibility of hydrogen fluoride release in the system and the damage caused to the TGA. Relative to the isoxazole series, the thermal stability of two amides and one thiourea was assessed by TGA. Amides were found to be more stable than thioureas, where both amides, $\mathbf{2 0}$ and $\mathbf{2 2}$ only show thermal degradation above $300{ }^{\circ} \mathrm{C}$, while thiourea $\mathbf{1 8 c}$ decomposed above $200{ }^{\circ} \mathrm{C}$ (Figure 4). Also, amides $\mathbf{2 0}$ and 22, which are isomers due to 


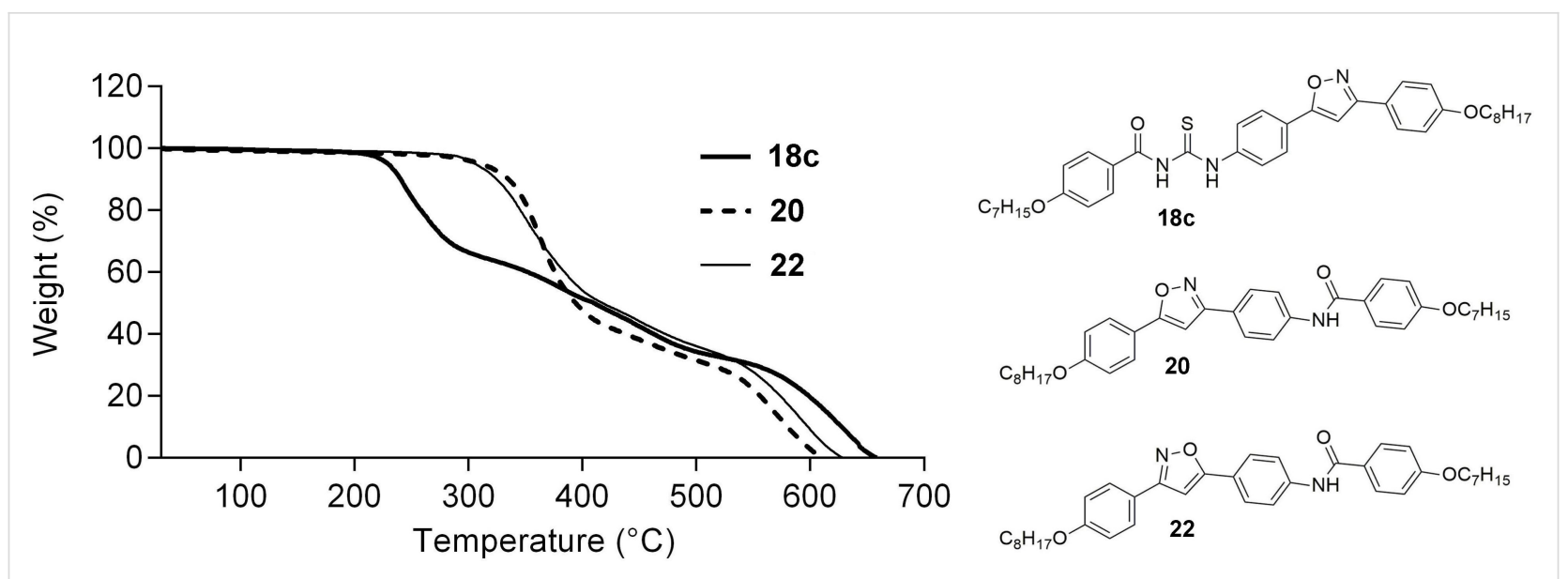

Figure 4: TGA analysis for thiourea 18c; and amides 20 and 22.

the change of the nitrogen and oxygen positioning in the isoxazole core, presented the same degradation behavior.

\section{Conclusion}

The results reported here are the first examples for the synthesis and characterization of a novel series of thiourea and amide LCs with isoxazoline and isoxazole scaffolds. All reactions proceeded smoothly and with good yields. From TGA analysis thioureas are less stable than amides as evidenced by their degradation temperature. The SmA mesophase was predominant for both thioureas and amides and the nematic mesophase was observed only for thioureas and amides containing the isoxazole ring. The mesophase range was dependent on the nature of the 5-membered heterocycle. The isoxazole derivatives showed a larger mesophase range than the isoxazoline derivatives.

\section{Supporting Information}

\section{Supporting Information File 1}

Experimental descriptions for the preparation of compounds and characterization data.

[https://www.beilstein-journals.org/bjoc/content/ supplementary/1860-5397-16-20-S1.pdf]

\section{Supporting Information File 2}

Differential scanning calorimetry plots of compounds. [https://www.beilstein-journals.org/bjoc/content/ supplementary/1860-5397-16-20-S2.pdf]

\section{Acknowledgements}

Thanks to Dr. Rômulo Faria Santos Canto of the Universidade Federal de Ciências da Saúde de Porto Alegre for the analyses of high-resolution mass spectrometry.

\section{Funding}

The authors wish to thank the Coordenação de Aperfeiçoamento de Pessoal de Nível Superior - Brasil (CAPES) - Finance Code 001 for the fellowships and Conselho Nacional de Pesquisa Científica (CNPq, edital Universal) for the financial support grant n. 403075 2016-5.

\section{ORCID ${ }^{\circledR}$ iDs}

Itamar L. Gonçalves - https://orcid.org/0000-0001-5952-6291 Vera L. Eifler-Lima - https://orcid.org/0000-0002-7656-9477 Aloir A. Merlo - https://orcid.org/0000-0002-8071-5297

\section{References}

1. Gonçalves, I. L.; de Azambuja, G. O.; Kawano, D. F.; Eifler-Lima, V. L. Mini-Rev. Org. Chem. 2018, 15, 28-35. doi:10.2174/1570193×14666170518125219

2. Štrukil, V. Beilstein J. Org. Chem. 2017, 13, 1828-1849. doi:10.3762/bjoc.13.178

3. Andrés, J. M.; Ceballos, M.; Maestro, A.; Sanz, I.; Pedrosa, R. Beilstein J. Org. Chem. 2016, 12, 628-635. doi:10.3762/bjoc.12.61

4. Bielenica, A.; Stefańska, J.; Stępień, K.; Napiórkowska, A.; Augustynowicz-Kopeć, E.; Sanna, G.; Madeddu, S.; Boi, S.; Giliberti, G.; Wrzosek, M.; Struga, M. Eur. J. Med. Chem. 2015, 101, 111-125. doi:10.1016/j.ejmech.2015.06.027

5. Makam, P.; Kannan, T. Eur. J. Med. Chem. 2014, 87, 643-656. doi:10.1016/j.ejmech.2014.09.086

6. Zalavadiya, P. D.; Ghetiya, R. M.; Dodiya, B. L.; Vekariya, P. B.; Joshi, H. S. J. Heterocycl. Chem. 2013, 50, 973-978. doi:10.1002/jhet.728

7. Gonçalves, I. L.; Rockenbach, L.; das Neves, G. M.; Göethel, G.; Nascimento, F.; Porto Kagami, L.; Figueiró, F.; Oliveira de Azambuja, G.; de Fraga Dias, A.; Amaro, A.; de Souza, L. M.; da Rocha Pitta, I.; Avila, D. S.; Kawano, D. F.; Garcia, S. C.; Battastini, A. M. O.; Eifler-Lima, V. L. Med. Chem. Commun. 2018, 9, 995-1010. doi:10.1039/c8md00095f 
8. Gonçalves, I. L.; Davi, L.; Rockenbach, L.; das Neves, G. M.; Kagami, L. P.; Canto, R. F. S.; Figueiró, F.; Battastini, A. M. O.; Eifler-Lima, V. L. Tetrahedron Lett. 2018, 59, 2759-2762. doi:10.1016/j.tetlet.2018.06.006

9. Azizi, N.; Khajeh-Amiri, A.; Ghafuri, H.; Bolourtchian, M. Mol. Diversity 2011, 15, 157-161. doi:10.1007/s11030-010-9236-7

10. Kato, T.; Hirai, Y.; Nakaso, S.; Moriyama, M. Chem. Soc. Rev. 2007, 36, 1857-1867. doi:10.1039/b612546h

11. Custelcean, R. Chem. Commun. 2008, 295-307. doi:10.1039/b708921j

12. Kishikawa, K.; Nakahara, S.; Nishikawa, Y.; Kohmoto, S.; Yamamoto, M. J. Am. Chem. Soc. 2005, 127, 2565-2571. doi:10.1021/ja046100c

13. Glettner, B.; Hein, S.; Reddy, R. A.; Baumeister, U.; Tschierske, C. Chem. Commun. 2007, 2596-2598. doi:10.1039/b703907g

14. Iliş, M.; Bucos, M.; Dumitraşcu, F.; Cîrcu, V. J. Mol. Struct. 2011, 987, 1-6. doi:10.1016/j.molstruc.2010.11.037

15. Sangeetha, N. M.; Maitra, U. Chem. Soc. Rev. 2005, 34, 821-836. doi:10.1039/b417081b

16. Duarte, R. da C.; Ongaratto, R.; Piovesan, L. A.; de Lima, V. R.; Soldi, V.; Merlo, A. A.; D'Oca, M. G. M. Tetrahedron Lett. 2012, 53, 2454-2460. doi:10.1016/j.tetlet.2012.03.015

17. Andreis, M.; Carić, D.; Vujičić, N. Š.; Jokić, M.; Žinić, M.; Kveder, M. Chem. Phys. 2012, 403, 81-88. doi:10.1016/j.chemphys.2012.05.013

18. Yu, X.; Chen, H.; Shi, X.; Albouy, P.-A.; Guo, J.; Hu, J.; Li, M.-H. Mater. Chem. Front. 2018, 2, 2245-2253. doi:10.1039/c8qm00340h

19. Fritsch, L.; Merlo, A. A. ChemistrySelect 2016, 1, 23-30. doi:10.1002/slct.201500044

20. Tavares, A.; Toldo, J. M.; Vilela, G. D.; Gonçalves, P. F. B.; Bechtold, I. H.; Kitney, S. P.; Kelly, S. M.; Merlo, A. A. New J. Chem. 2016, 40, 393-401. doi:10.1039/c5nj02199e

21. da Rosa, R. R. Isoxazolinas e isoxazóis como reais candidatos na preparação de cristais líquidos polares. Ph.D. Thesis, Universidade Federal do Rio Grande do Sul, 2018.

22. Lopes, L. D.; Merlo, A. A. Mol. Cryst. Liq. Cryst. 2015, 612, 149-157. doi:10.1080/15421406.2015.1030972

23. Vilela, G. D.; da Rosa, R. R.; Schneider, P. H.; Bechtold, I. H.; Eccher, J.; Merlo, A. A. Tetrahedron Lett. 2011, 52, 6569-6572. doi:10.1016/j.tetlet.2011.09.122

24. Tavares, A.; Ritter, O. M. S.; Vasconcelos, U. B.; Arruda, B. C.; Schrader, A.; Schneider, P. H.; Merlo, A. A. Liq. Cryst. 2010, 37, 159-169. doi:10.1080/02678290903432098

25. Schneider, J. M. F. M.; Sales, E. S.; Livotto, P. R.; Schneider, P. H.; Merlo, A. A. J. Braz. Chem. Soc. 2014, 25, 1493-1503. doi:10.5935/0103-5053.20140132

26. Tschierske, C. Fluorinated Liquid Crystals: Design of Soft Nanostructures and Increased Complexity of Self-Assembly by Perfluorinated Segments. Liquid Crystals; Topics in Current Chemistry, Vol. 318; Springer: Berlin, Heidelberg, Germany, 2011; pp 1-108. doi:10.1007/128_2011_267

27. Fritsch, L.; Baptista, L. A.; Bechtold, I. H.; Araújo, G.; Mandle, R. J.; Merlo, A. A. J. Mol. Liq. 2020, 298, No. 111750. doi:10.1016/j.molliq.2019.111750

28. Bushby, R. J.; Lozman, O. R. Curr. Opin. Colloid Interface Sci. 2002, 7, 343-354. doi:10.1016/s1359-0294(02)00085-7

29. Hariprasad, S.; Srinivasa, H. T. Liq. Cryst. 2015, 42, 1612-1620. doi:10.1080/02678292.2015.1078918

30. Lu, L.-Y.; Kuo, H.-M.; Sheu, H.-S.; Lee, G.-H.; Lai, C. K. Tetrahedron 2014, 70, 5999-6011. doi:10.1016/j.tet.2014.05.036

31. Pongali Sathya Prabu, N.; Madhu Mohan, M. L. N. Phase Transitions 2013, 86, 339-360. doi:10.1080/01411594.2012.682729
32. Rajanandkumar, R.; Prabu, N. P. S.; Mohan, M. L. N. M. Mol. Cryst. Liq. Cryst. 2016, 626, 193-206. doi:10.1080/15421406.2015.1106879

\section{License and Terms}

This is an Open Access article under the terms of the Creative Commons Attribution License (https://creativecommons.org/licenses/by/4.0). Please note that the reuse, redistribution and reproduction in particular requires that the authors and source are credited.

The license is subject to the Beilstein Journal of Organic Chemistry terms and conditions:

(https://www.beilstein-journals.org/bjoc)

The definitive version of this article is the electronic one which can be found at: doi: $10.3762 /$ bjoc. 16.20 